1. MBBS, FCPS

Associate Professor

Department of Orthopaedic Surgery and Traumatology

Liaquat medical university Hospita jamshoro

2. MBBS, MS

Assistant professor

Department of Orthopaedic Surgery and traumatology

Liaquat medical university Hospital Jamshoro

3. MBBS, MS

Consultant Orthopaedic Surgeon Department of

Liaquat Medical University Hospital jamshoro

4. MBBS

Liaquat University Hospital

Hyderabad

Correspondence Address: Dr. Muhammad khan pahore National Medical Center

Khursheed Town Hala Naka

Hyderabad.

m.khanpahore@hotmail.com

dr.sajidarain@gmail.com

Article received on:

04/08/2014

Accepted for publication:

09/09/2014

Received after proof reading:

$16 / 10 / 2014$

\section{FEMORAL NECK FRACTURE;}

\section{OUTCOME OF UNIPOLAR HEMIARTHOPLASTY IN ELDERLY PATIENTS}

\author{
Dr. Muhammad Ayub Laghari', Dr. Muhammad Khan Pahore², Dr. Imran Khan Maher', \\ Dr. Muhammad Saeed Arain ${ }^{4}$
}

ABSTRACT... Objective: Objective of this study determines the outcome of unipolar hemiarthoplasty in elderly patients with femoral neck fracture at Liaquat University Hospital Hyderabad/ Jamshoro. Materials and methods: Total 50 elderly patients were included in the study with femoral neck fracture and all the cases were selected from accident, emergency and OPD. All the patients with the history of pregnancy, those patients who were unfit for anesthesia, malignancy, neurological deficits of lower extremity, rheumatoid arthritis and Parkinson's disease regarding with systemically disease were excluded from the study. All the patients under went surgical hemiarthoplasty treatment with Austin moor-femoral head prosthesia. In the last all postoperative complications, functional outcome and mortality were noted on proforma. Results: Total 50 patients were included in the study. Mean age of this study was mean $\pm S D$ $64.98 \pm 4.13$. Females were found in majority with male/ female ratio 1:1.27. Post operative pain was noted in the $50 \%$ of the cases and out of them severe pain was noted only in $4 \%$ of the cases. Superficial infection was seen in $4 \%$ of the cases and deep infection was not found in the cases and death was occurred in $10 \%$ of the patients. On the outcome, excellent results were found in the $44.44 \%$ of the study participants, good and fair results were seen in $26.66 \%$ and $20 \%$ respectively, while poor results were seen in $8.88 \%$ of the patients. Conclusions: It is concluded that unipolar hemiarthoplasty is of the reliable procedure by use of Austin-moor femoral head prosthesia for the treatment of femoral neck fracture in elderly.

Key words: $\quad$ Unipolar Hemiarthoplasty, femur neck fracture, elderly patients.

Article Citation: Laghari MA, Pahore MK, Maher IK, Arain MS. Femoral neck fracture; outcome of unipolar hemiarthoplasty in elderly patients. Professional Med J 2014;21(5):874-878.

\section{INTRODUCTION}

Femoral neck fractures, is the very common injuries in the elderly patients, and also a great challenges to orthopaedic surgeons. Its incidence continuously increasing according to the demographic estimation in the future ${ }^{1,2}$. Mostly in the elderly patients femoral neck fractures characterize a significant health care problem and have enormous impact on health insurance costs. Prevalence of hip fractures related to osteoporosis is progressively increasing ${ }^{3,4}$. In Germany, a rise of $74 \%$ in prevalence of proximal femoral fractures until the year 2020 is forecasted, ${ }^{4}$ and further more a currently in hospital mortality of $8.6 \%$ was described in over 85 year old patients. This kind of fractures having high morbidity and mortality ${ }^{4,5}$.

Nowadays surgeon may able to select the hemiarthoplasty for the fracture neck of femur and or internal fixation with cannulated screw or DHS, and unipolar hemiarthroplasty, bipolar hemiarthroplasty and total hip arthroplasty in the treatment of femur neck fracture ${ }^{6}$.
The open reduction and internal fixation having many complications like, non union, AVN and increase morbidity and mortality with long time. Unipolar hemiarthroplasty with Austin Moore prosthesis is rarely employed in the developed countries though it is very commonly used in developing countries like India. It should ideally be reserved for very limited or nonambulatory patients ${ }^{7}$.

Internationally surgeons treat older patients similar to younger ones by CRIF using cannulated screws or devices like the sliding hip screw. For this dissimilarity, reconstruction options are including; hemiarthroplasty; unipolar, bipolar and total hip arthroplasty. Therefore, the optimal treatment of this patient population is still under debate ${ }^{8}$. The bipolar and total hip arthoplasty are costly and having technical demanding surgeries. The unipolar hemiarthoplasty with Austin moor is cost affect easy available and having less morbidity and mortality and patients can walk on their own feet in few days after surgery. So the purpose of this study to determine the outcome efficacy including postoperative complications of Austen Moor Hemiarthoplasty in 
elderly patients with femoral neck fracture at Liaquat university Hospital Hyderabad/ jamshoro.

\section{MATERIAL AND METHODES}

This observational and prospective study was carried out at orthopedic department of Liaquat University hospital Hyderabad/ Jamshoro. Total 50 elderly patients were included in the study with femoral neck fracture and all the cases were selected from the emergency and OPD. This study was conducted with duration of the time of January 2011 to December 2013. Informed written consent was taken from the every patient's attendant and also informed about patient's conditions. All the patients with the history of pregnancy, having non ambulatratory status before fracture, malignancy, neurological deficits of lower extremity, rheumatoid arthritis and Parkinson's disease regarding with systemically disease were excluded from the study. Complete physical examination, basic history of fracture radiological diagnosis and routine laboratory investigations were done. All the patients under went surgical unipolar hemiarthoplasty treatment with use of Austin-moor femoral prosthesia. All the patients were fastened an addiction pillow on operated leg with crepe bandage post operatively, to protect the leg from postoperative dislocation for 10 to 14 days according to the patient's compliance and co-operation. All the patients were allowed to sit and light exercise of foot and leg on next day of surgery. In the follow up protocol patients were kept in the ward of Hospital for 7 to 15 days. After 15 days patients were called every 15 days in OPD for one month and then patients called for monthly checkup for three months. In the last maximum 6 month to 1 year all postoperative complications, functional outcome and mortality were noted on written Proforma.

\section{RESULTS}

Total 50 patients were included in the study 22 male and 28 females. Mean age of this study is mean \pm SD $64.98 \pm 4.13$. Females were found in majority with male/ female ratio $1: 1.27$. Table-l.

\begin{tabular}{|c|c|}
\hline Mean & 64.98 \\
\hline Std. Deviation & 4.13 \\
\hline Range & $<59$ \\
\hline Male/ Female $=$ Ratio & $22 / 28=1: 1.27$ \\
\hline Table-l. Age and gender distribution $(n=50)$ \\
\hline
\end{tabular}

All the fractures were graded according to the Garden's classification and $39 . \%$ of patients were noted with grade III while $61 \%$ were noted with grade IV. FIG:1.

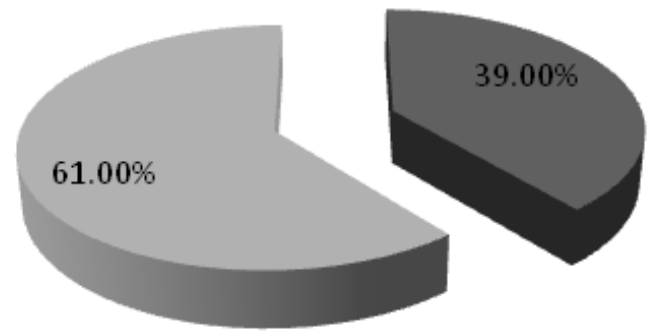

- Grade III Grade IV

Fig-1. Fracture grades according to garden type $(n=50)$

Majority of the patients $62 \%$ of cases reported with history of fall after them $40 \%$ of the cases were slipped and $22 \%$ fallen from the height, while $38 \%$ of the cases were with the history of road traffic accident. Table-II.

\begin{tabular}{|c|c|}
\hline Mode of injury & No. of patients/\%age \\
\hline Fall (Slip) & $20 /(40.0 \%)$ \\
\hline Fall (from height) & $11 /(22.0 \%)$ \\
\hline RTA & $19 /(38.0 \%)$ \\
\hline Table-II. Mode of injury $n=50$
\end{tabular}

Regarding to the complications pain was noted in the $50 \%$ of the cases and out of them severe pain was noted only in $4 \%$ of the cases. Superficial infection was seen in $4 \%$ of the cases and no deep infection was noted in the cases. $6 \%$ patients were showed with bed sores, UTI was in $8 \%$, and dislocation of prosthesis was seen in the $0 \%$ of the cases, while according to the mortality, death was occurred in $10 \%$ of the patients. Table-III.

\begin{tabular}{|c|c|}
\hline Complications & No. of patients/\%age \\
\hline Pain & \\
Mild & $15 /(30.0 \%)$ \\
Moderate & $8 /(16.0 \%)$ \\
Severe & $2 /(4.0 \%)$ \\
Infection & $2 /(4.0 \%)$ \\
Superficial & $0 /(0 \%)$ \\
Deep & $4 /(8.0 \%)$ \\
UTI & $3 /(6.0 \%)$ \\
Bed sore & $0 /(0 \%)$ \\
Dislocation & $5 /(10.0 \%)$ \\
\hline Table-III. Post-operative complications n=50
\end{tabular}


Functional outcome in 45 remaining patients was recorded according to $\mathrm{D}$, Arcy et al scoring system, as well as excellent successful results were found in the $44.4 \%$ of the study participants, good and satisfied results were seen with the percentage of $26.66 \%$ and $20.0 \%$ respectively, while poor results were seen in $8.88 \%$ of the patients. Table-IV

\begin{tabular}{|c|c|c|}
\hline & Frequency & $\%$ \\
\hline Excellent & 20 & $44.4 \%$ \\
Good & 12 & $26.66 \%$ \\
Fair & 09 & $20.0 \%$ \\
Poor & 04 & $8.88 \%$ \\
\hline \multicolumn{2}{|c|}{ Table-IV. Outcome by D, Arcy et al scoring system. } \\
\hline \multicolumn{2}{|c|}{$\mathrm{n}=45$} \\
\hline
\end{tabular}

\section{DISCUSSION}

Femoral neck fractures, one of the most common injuries in the elderly, have always presented great challenges to orthopaedic surgeons. The incidence of these fractures has increased with improvement in life expectancy and is expected to double in the next 20 years and triple by $2050^{9}$. The goal of treatment of femoral neck fractures is restoration of pre-fracture function without associated morbidity ${ }^{10}$. Experience of the last four decades has shown that hemiarthroplasty is the best treatment for intracapsular fracture neck of femur in elderly in terms of both short-term and longterm results ${ }^{11}$.

In the study of Jadhav AP et al, ${ }^{12}$ reported mean age 65.7, Onche and Yinusa ${ }^{13}$ showed mean age in the study 67.4, in another study of Essoh J.B. Sié M.D et al reported range of the age 55-88 years with the slandered deviation of $7.2^{14}$. Similarly in this study mean age was showed as mean \pm SD $64.98 \pm 4.13$. In the study of Ahmed I, 15 reported male female ratio was $1: 2$. While in this study female were in the majority as compare to male with the male/female ratio of $1: 1.27$.

In the study of Shrinivas Kalliguddi et al ${ }^{16} 9$ cases (45\%) affected were due to Slip and Fall, 8 cases (40\%) due to RTA, and 3 cases (15\%) due to Fall from height. Slip and fall was the most common mode of injury. As well as in this study Majority of the patients were come with the falling out of them $40 \%$ were slipped and $22 \%$ were felled from height, while $38 \%$ of the cases were come with road traffic accident.

In a study performed by Essoh J.B. Sié M.D et al, ${ }^{14}$ showed fracture types according to garden $32.1 \%$ patients with fracture grade III and $67.9 \%$ patients with grade IV. Similarly in this study according to the Garden and $39 . \%$ of patients were noted with grade III while $61 \%$ were noted with grade IV.

According to the study of Barnes CL et all, ${ }^{17}$ dislocation rate was $1.5 \%$. Other authors reported $4 \%$ dislocation rate $^{18,19}$. Noor SS. ${ }^{20}$ reported $0 \%$ dislocation in their study with unipolar hemiarthoplasty. We have $0 \%$ dislocation rate because we fasten adduction pillow to the leg postoperatively for 1 to 2 weeks, along with care full shifting of the patients from theater table to the bed and also for X-ray. Postoperative wound infection $0 \%$ reported by Noor $S S,{ }^{20}$ and $7.5 \%$ reported by Dinesh Dhar $^{21}$. In general duration of operation has been proven conclusively to be a potent risk factor in the development of postoperative infection ${ }^{13}$. We have only $4 \%$ superficial infection was noted because all the surgeries were performed by senior surgeons having less operating time with pre and post antibiotic cover and the special care was taken for patients hygiene and theater condition.

Mortality rate reported by Somashekar et al ${ }^{22} 9.5 \%$ in the patients treated with unipolar hemiarthoplasty and Aharonoff GB et $a^{23}$ reported $11.77 \%$. Essoh J.B. Sié M.D et al, ${ }^{14}$ reported mortality rate $8.3 \%$ in the patients treated with Austin moor hemiarthoplasty. Mortality at six months is $13.5 \%$ overall $^{22}$ and one year mortality rate following hip fracture surgery is remarkably high, and is usually around $26 \%{ }^{24}$. While in the present study mortality rate was only $10 \%$, in our series mean age was 64.98 having less co morbidities, while in other series age was above 70 years mostly including with severe co morbidities which was causing high mortality rate.

In the study of Anshu Shekhar et $\mathrm{al}^{7}$ reported outcome of hemiarthoplasty treatment in patients with femoral neck fracture as, excellent $43.5 \%$, good $38.4 \%$, fair $11.3 \%$ and poor $6.8 \%$. Dinesh Dhar et al ${ }^{21}$ reported outcome of of austen moor in femor neck fracture outcome excellent $80.2 \%$ and fair $19.8 \%$. Noor SS et $\mathrm{al}^{20}$ reported outcome as, excellent $38 \%$, good $21 \%$, fair $24 \%$ and poor $17.3 \%$. Similarly in the present study outcome in 45 remaining patients was as; the excellent results were found in the $44.44 \%$ of the study participants, good and satisfied results were seen with the percentage of $26.66 \%$ and $20 \%$ respectively, while poor results were seen in $8.88 \%$ of the patients.

\section{CONCLUSIONS}

In the conclusion of this study the main cause of the injuries is falling and RTA which may reduced by good care of elders and driving should be carefully 
mostly of motorcycle, further more the Austen Moor Hemiarthoplasty (unipolar) is the good surgical treatment for the femur neck fracture. It is commonly available, cost effect with less morbidity and mortality. Copyright@ 09 Sep, 2014.

\section{REFRENCES}

1. Miyamoto RG, Kaplan KM, Levine BR, Egol KA, and Zuckerman JD: Surgical management of hip fractures: an evidence-based review of the literature. I: femoral neck fractures. J Am Acad Orthop Surg 2008, 16:596607.

2. Simonen O: Incidence of femoral neck fractures: senile osteoporosis in Finland in the years 19701985. Calcif Tissue Int 1991, 49(Suppl):8-10.

3. Becker DJ, Kilgore ML, Morrisey MA: The societal burden of osteoporosis. Curr Rheumatol Rep 2010, 12(3):186-191.

4. Frerichmann U, Raschke MJ, Stockle U, Wohrmann S, Lohmann R: Proximal femoral fractures in the elderly. Data from health insurance providers on more than 23 million insured persons--part 2. Unfallchirurg 2007,110(7):610-616.

5. Roche JJ, Wenn RT, Sahota O, Moran CG: Effect of comorbidities and postoperative complications on mortality after hip fracture in elderly people: prospective observational cohort study. BMJ 2005,331 (7529): 1374.

6. Ioro R, Schwartz B, Macaulay W, Teeney SM, Healey WL, York S. Surgical treatment of displaced femoral neck fractures in the elderly: a survey of the American Association of Hip and Knee Surgeons. J Arthroplasty 2006; $21(8): 1124-1133$.

7. Dr. Anshu Shekhar1, Dr. Gururaj Murgod2, Dr. Suresh Korlhalli3. Two years outcome of cemented Austin Moore hemiarthroplasty for fracture neck femur. Journal of Dental and Medical Sciences.2013; 11; 6:1015.

8. Dai Z, Li Y, Jiang D: Meta-Analysis Comparing Arthroplasty with Internal Fixation for Displaced Femoral Neck Fracture in the Elderly. J Surg Res 2011 Jan;165(1):68-74.

9. Schmidt $A H$, Swiontkowski MF. Femoral neck fractures. Orthop Clin North Am 2002; 33(1):97-111.

10. Ioro R, Healy WL, Lemos DW, Appleby D, Lucchesi $\mathrm{C}$, Saleh $\mathrm{KJ}$, et al. Displaced femoral fractures in the elderly : outcomes and cost effectiveness. Clin Orthop 2001; 383: 229-242.
11. Bhandari M, Devereaux PJ, Swiontowski MF, Tornetta $\mathrm{P}$, Obremskey W, Koval KJ, et al. Internal fixation compared with arthroplasty for displaced fractures of the femoral neck. J Bone Joint Surg Am 2003; 85A:1673-1681.

12. Jadhav AP, Kulkarni SS, Vaidya SV, Divekar MM, Suralkar SP. Results of Austin Moore replacement. J Postgrad Med 1996; 42:33-8.

13. Onche II, Yinusa W. Femoral neck fractures: A prospective assessment of the pattern, care and outcome in an orthopaedic centre. Nigerian Journal of Orthopaedics and Trauma 2004; 3:42-9.

14. Essoh J.B. Sié M.D, Aka D. Kacou M.D, M Kodo M.D, Y Lambin M.D. Austin Moore Hemiarthroplasty For Displaced Femoral Neck Fractures In Patients Aged 55 Years And Above. An Ivorian Experience. NJOT June 2006;5;1:8-13.

15. Ahmad I. Mortality and morbidity in elderly patients with fracture neck of femur treated by hemiarthroplasty. J Coll Physicians Surg Pak. 2006 Oct;16(10):655-8.

16. Shrinivas Kalliguddi, Veerabhadra Jawali and Reneesh UP*. Proximal Femoral Nail in the Mangement of Peritrochanteric Fractures Femur and its Functional Outcome. Vol. 4 (4) Oct - Dec 2013:1276-86.

17. Barnes CL, Berry DJ, Sledge CB: Dislocation after bipolar hemiarthroplasty of the hip. J Arthroplasty 1995, 10:667-669.

18. Figved W, Norum OJ, Frihagen F, Madsen JE, Nordsletten L: Interprosthetic dislocations of the Charnley/ Hastings hemiarthroplasty-report of 11 cases in $\mathbf{3 5 0}$ consecutive patients. Injury 2006, 37:157-161.

19. Figved W, Dybvik E, Frihagen F, Furnes O, Madsen $\mathrm{JE}$, Havelin LI, et al: Conversion from failed hemiarthroplasty to total hip arthroplasty: a Norwegian Arthroplasty Register analysis of 595 hips with previous femoral neck fractures. Acta Orthop 2007, 78:711-718.

20. Noor SS, Hussain N, Javed I. Outcome of Austin Moore hemiarthroplasty in elderly patients with fracture neck of femur. $\mathrm{J}$ of Pakistan Orthopaedic Association 2010; 22(1): 14-19.

21. Dinesh Dhar. Early Results of Austin Moore Prosthesis in Elderly Patients with fracture neck femur. J.Orthopaedics 2007;4(1)e3.

22. Somashekar, MS, Sathya Vamsi Krishna, MS, Sridhara Murthy JN, MS . Treatment of Femoral Neck Fractures: Unipolar Versus Bipolar Hemiarthroplasty. Malaysian 
Orthopaedic Journal 2013;7;3:6-11.

23. Aharonoff GB, Immerman I, Zuckerman JD. Outcomes after hip fracture. Tech Orthop 2004;19:229-34.
24. Casaletto JA, Gatt R. Post-operative mortality related to waiting time for hip fracture surgery. Injury 2004; 35:114-20.

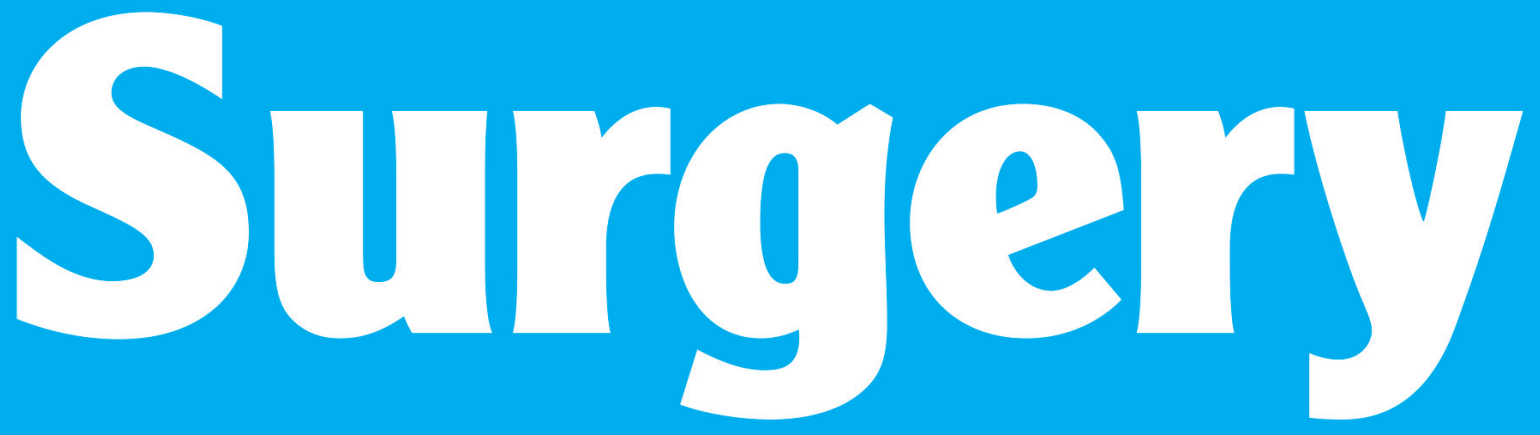

4th Edition | Volume-I

\section{TELL ME THE ANSWER}

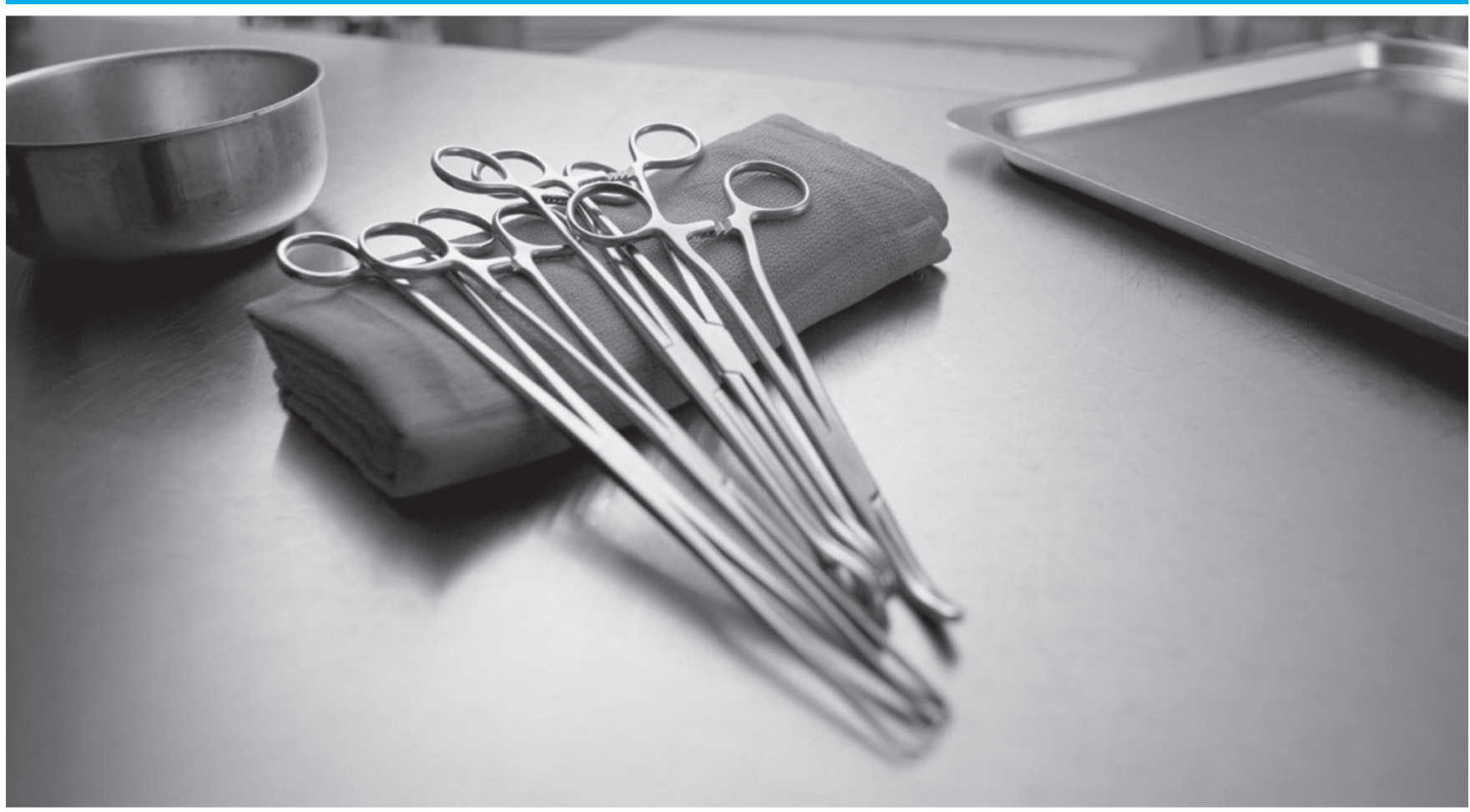

